\title{
A importância da porta de entrada no sistema: o modelo integral de cuidado para o idoso
}

\author{
I ${ }^{1}$ Martha Regina de Olveira, ${ }^{2}$ Renato Peixoto Veras, \\ ${ }^{3}$ Hésio de Albuquerque Cordeiro I
}

Resumo: A literatura mostra que a prestação de serviços aos idosos deve ser mais eficiente. Usuários necessitam de serviços que integrem atenção primária e demais serviços, além de equipe de saúde qualificada. O plano de cuidados e a gestão são elementos-chave para o sucesso da assistência. Há necessidade de modificar o modelo assistencial, a começar pela integração e coordenação dos serviços. Este texto é baseado em dois experimentos bem-sucedidos de modelos assistenciais para idosos, o da UnATI-UERJ e do Projeto Idoso Bem-Cuidado, iniciativa da Agência Nacional de Saúde Suplementar, que propóe um modelo inovador de atenção. Ambos são compostos por cinco níveis hierarquizados de cuidado: (1) acolhimento, (2) núcleo integrado de cuidado, (3) ambulatório geriátrico, (4) cuidados complexos de curta duração e (5) cuidados longa duração, nos quais se destacam os três primeiros, nas instâncias leves de cuidado. Identificação do risco e integralidade da atenção nos diferentes pontos da rede são o cerne deste modelo. O principal compromisso do projeto é melhorar a qualidade e a coordenação do atendimento desde a porta de entrada do sistema e ao longo do cuidado, com consequente utilização mais adequada dos recursos e melhor resultado para o paciente.

> Palavras-chave: idoso; serviços de saúde; assistência integral à saúde; qualidade da assistência à saúde; inovação.

\footnotetext{
1 Doutorado, Programa de PósGraduação em Ciências Médicas, Universidade do Estado do Rio de Janeiro. Rio de Janeiro-RJ, Brasil (martha@scaff.med.br). ORCID: 0000-0003-1485-777X

2 Universidade do Estado do Rio de Janeiro, Universidade Aberta da Terceira Idade. Rio de JaneiroRJ, Brasil (unativeras@gmail.com) ORCID: 0000-0002-2499-1801

${ }^{3}$ Universidade do Estado do Rio de Janeiro, Universidade Aberta da Terceira Idade. Rio de JaneiroRJ, Brasil (hesioalbuquerque@ gmail.com). ORCID: 0000-0002-3208-8241
}

Recebido em: 25/10/2017 Revisado em: 02/07/2018 Aprovado em: 13/09/2018 


\section{Introdução}

O idoso tem particularidades bem conhecidas - mais doenças crônicas e fragilidades, mais custos, menos recursos sociais e financeiros. Envelhecer, ainda que sem doenças crônicas, envolve alguma perda funcional. Com tantas situaçóes adversas, o cuidado do idoso deve ser estruturado de forma diferente da que é realizada para o adulto mais jovem.

A atual prestação de serviços de saúde fragmenta a atenção ao idoso, com multiplicação de consultas de especialistas, informação não compartilhada, inúmeros fármacos, exames clínicos e de imagens, entre outros procedimentos. Sobrecarrega o sistema, provoca forte impacto financeiro em todos os níveis e não gera benefícios significativos para a saúde, nem para a qualidade de vida (VERAS; CALDAS; CORDEIRO, 2013). Paralelamente, a projeção demográfica para os próximos anos aponta uma população ainda mais envelhecida - assim, o panorama atual só tende a piorar se o modelo assistencial se mantiver inalterado.

A literatura sobre a saúde reforça a necessidade de promoção e educação em saúde, da prevenção e do retardamento de doenças e fragilidades, da manutenção da independência e da autonomia. Entre gestores e profissionais de saúde, este discurso é aceito, mas na prática tais ações não são exercidas. Fala-se algo e pratica-se uma assistência diferente (BRASIL, 2013).

Este texto, além de defender uma assistência baseada em um modelo contemporâneo de saúde para com o idoso, propóe persuadir os gestores a aplicar um modelo que reúna um fluxo de açôes de educação, promoção da saúde, prevenção de doenças evitáveis, postergação de moléstias, cuidado precoce e reabilitação de agravos. Defende-se uma linha de cuidado ${ }^{1}$ para o idoso que apresente eficiência e eficácia, e para tal deve-se pressupor uma rede articulada, referenciada e com um sistema de informação desenhado em sintonia com essa lógica. Ênfase especial é conferida ao início do processo, a porta de entrada no sistema de saúde, pois não é possível estabelecer uma interação pautada pela confiança entre o prestador de serviço e o paciente se náo houver desde o início uma relação regida pela transparência e qualidade.

Dividimos os vários momentos do plano de cuidado ao idoso em cinco fases e todas serão abordadas, mas é o nível um, o início do processo, o foco deste trabalho. 


\section{Metodologia}

Foi realizada vasta revisão bibliográfica sobre o tema. Posteriormente, foi descrito um modelo para o cuidado ao idoso no Brasil, em especial na saúde suplementar, através da fusão desses modelos estudados e da percepção das necessidades de mudança no nosso atual modelo.

\section{O modelo assistencial atual}

Os sistemas de saúde funcionam com poucos pontos de atenção - os quais não funcionam de forma integrada. Em geral, os pacientes entram nessa rede desarticulada em um estágio muito avançado. A porta de entrada acaba sendo a emergência do hospital. Além de inadequado e anacrônico (funciona da mesma forma desde os anos 1970), esse modelo apresenta péssima relação custo-benefício, pois é centrado no hospital, faz uso intensivo de tecnologias de alto custo, além de tentar tratar agudamente de doenças que são crônicas. Seu fracasso, no entanto, não deve ser imputado aos usuários, alegando que gostam de consumir, nem ao profissional de saúde, pois o modelo ensinado nas escolas de saúde é o do hospital e da doença. Envelhecemos, mudamos nosso perfil epidemiológico, mas a organização do sistema de saúde não mudou. Temos que atacar o erro, ou seja, o modelo assistencial praticado, pois há sobrecarga de usuários nos níveis de maior complexidade, pela carência de cuidado nos primeiros níveis.

Um dos problemas da maioria dos modelos assistenciais vigentes decorre do foco exclusivo na doença. Mesmo quando se oferece um programa com uma lógica de antecipação dos agravos, as propostas são voltadas, prioritariamente, para a redução de determinada moléstia, esquecendo que numa doença crônica já estabelecida o objetivo não deve ser a cura, mas a busca da estabilização do quadro clínico e o monitoramento constante, de forma a impedir ou amenizar o declínio funcional (VERAS; ESTEVAM, 2015).

Estudos evidenciam que a atenção deve ser organizada de maneira integrada e os cuidados precisam ser coordenados ao longo do percurso assistencial, numa lógica de rede desde a entrada no sistema até os cuidados ao fim da vida (MENDES et al., 2004). Portanto, os adequados modelos de atenção à saúde para idosos são aqueles que apresentam uma proposta de linha de cuidados, com foco em açôes 
de educação, promoção da saúde, prevenção de doenças evitáveis, postergação de moléstias, cuidado precoce e reabilitação (VERAS et al., 2014).

O modelo deve ser baseado na identificação precoce dos riscos de fragilização dos usuários. Uma vez identificado o risco, a prioridade é a reabilitação precoce, a fim de reduzir o impacto das condiçóes crônicas na funcionalidade - busca-se intervir antes de o agravo ocorrer. A ideia é monitorar a saúde, não a doença; a intenção é postergar a doença, a fim de que o idoso possa usufruir seu tempo a mais de vida com qualidade. Assim, a melhor estratégia para um adequado cuidado do idoso é utilizar a lógica de permanente acompanhamento da sua saúde, tê-lo sempre sob observação, variando apenas os níveis, a intensidade e o cenário da intervenção (VERAS et al., 2013).

Esse modelo teórico tem uma lógica pragmática, implicada na viabilidade de implantação e baseada em resultados mensuráveis. Tal lógica é aplicável a qualquer rede de atenção ao idoso, seja pública ou privada. No entanto, devido ao tamanho do Sistema Único de Saúde (SUS) e às imensas diferenças político-estruturais entre os municípios que o compóem, este modelo termina por se voltar para o setor privado, uma vez que, na saúde suplementar, a desarticulação e as deficiências de organização da rede assistencial são ainda maiores. Apesar desta afirmação, trabalhamos para que em um futuro próximo, após o experimento no setor privado, possa ele também servir como uma possibilidade para todos os idosos no Brasil.

Visando à eficácia do modelo assistencial, deve-se ampliar a gestão da informação, valorizar o conhecimento científico e reduzir o poder absoluto das máquinas de diagnóstico. Torna-se necessário mudar a lógica assistencial, que se encontra defasada. Os gestores devem buscar intervençôes que visem usar corretamente as instâncias avançadas de cuidado (entre elas, o hospital), ampliar a oferta de cuidados em instâncias mais leves (entre as quais, o núcleo integrado de cuidado), sempre que possível em caráter preventivo, fora do ambiente hospitalar. ${ }^{2}$

A estruturação da rede possibilita pelo menos dois elementos fundamentais para o cuidado do idoso: a diminuição de iatrogenia e a organização do fluxo de cuidados. As diretrizes e os protocolos clínicos também são essenciais na construção do projeto terapêutico. Eles devem direcionar a boa prática, ser pautados na melhor evidência disponível e adequados a cada situação clínica. O plano terapêutico é o fio condutor para o fluxo da linha do cuidado, e esta estabelece o percurso assistencial de acordo com suas necessidades (VERAS et al., 2013). 
Existem algumas sugestóes de modelos de linhas de cuidado. $\mathrm{O}$ importante é que cada instituição de saúde tenha conhecimento de sua carteira, seu perfil e necessidades, de modo a construir a melhor forma de organizar sua prestação de serviços. Deve-se desenhar um modelo em que haja várias instâncias de cuidado anteriores ao hospital, que é equivocadamente visto como local privilegiado da cura. Este é um erro conceitual. A internação de pessoas idosas deve apenas ocorrer no momento agudo da doença crônica, pelo menor tempo possível ou em casos de urgências (VERAS et al., 2014).

A proposta de linha de cuidado ao idoso deve ser compreendida como uma estratégia de estabelecimento de "percursos assistenciais", organizando o fluxo de indivíduos de acordo com seu grau de fragilidade. A identificação do risco e a integralidade da atenção nos diferentes pontos da rede são o cerne desse modelo. A linha de cuidado poliárquica não pressupóe um percurso evolutivo entre os níveis de atenção do modelo, as etapas não podem ser absolutamente fixas, porque existe a possibilidade de reversão da incapacidade e retorno a um patamar de menor complexidade, dependendo da situação.

\section{O modelo proposto}

O modelo proposto é estruturado em cinco níveis, conforme apresentado na figura 1. Devemos considerar, no entanto, que os níveis 1 a 3, em laranja são as instâncias leves, ou seja, de custos menores e compostas basicamente pelo cuidado dos profissionais de saúde, todos bem treinados, e pela utilizaçáo de instrumentos epidemiológicos de rastreio e pelo uso de tecnologias de monitoramento de saúde. O esforço deve ser realizado para manter os pacientes nesses níveis leves, visando preservar sua qualidade de vida e sua participação social. Já as instâncias em marrom, as pesadas, são de alto custo e é onde se situam o hospital e as unidades de longa permanência. $\mathrm{O}$ empenho deve ser para tentar reabilitar o paciente e trazêlo para as instâncias leves, apesar de nem sempre ser possível. Busca-se, portanto, permanecer com o idoso nos três primeiros níveis de cuidado, com vistas a preservar sua qualidade de vida e reduzir os custos.

A meta é concentrar nessas instâncias mais de 90\% dos idosos (VERAS et al., 2015). Sabemos que nem sempre é possível manter todos os clientes nas instâncias leves, mas é importante reforçar que, ao se falar que desejamos que todos os clientes 
fiquem nas instâncias iniciais do modelo, não se trata de impedir a sua progressão nas instâncias mais pesadas. A utilização do hospital, por exemplo, deve ser uma exceção, se possível pelo menor tempo, e para tal organizamos a estratégia do cuidado integral e do monitoramento intenso.

Os modelos de atenção para este segmento etário precisam ser centrados na pessoa, considerando suas necessidades especiais. $\mathrm{O}$ cuidado deve ser gerenciado desde a entrada no sistema até o fim da vida, com acompanhamento constante. Os idosos possuem especificidades decorrentes de doenças crônicas, de fragilidades orgânicas e sociais (VERAS; AMORIM, 2015). A reprodução gráfica do modelo auxilia na compreensão de aspectos importantes do modelo proposto. A entrada através do nível 1 (acolhimento) ${ }^{3}$ garante um acesso consciente, um início pautado na transparência das regras de funcionamento, das carências, bonificaçóes e premiaçôes (caso o cuidado seja organizado por uma operadora de planos de saúde), dos direitos e deveres, da atenção ofertada. Constitui-se, portanto, a porta de entrada de um momento crucial para estabelecimento da empatia e da confiança, elementos fundamentais para a fidelização do usuário ao projeto.

Outro diferencial importante é a proposição de registrar os "percursos assistenciais" do paciente por meio de um sistema de informação amplo e de qualidade, que registre não somente a evolução clínica da pessoa idosa, mas também sua participação em ações de prevenção, individuais ou coletivas, assim como o apoio do gerente de acompanhamento (navegador) e as chamadas telefônicas realizadas para ou pelo GerontoLine $^{4}$ (que será comentado mais adiante). Isto permite um compartilhamento da informação com a equipe, possibilitando avaliação mais integral do indivíduo. 
Figura 1. Modelo Brasileiro de Cuidado Integrado ao Idoso

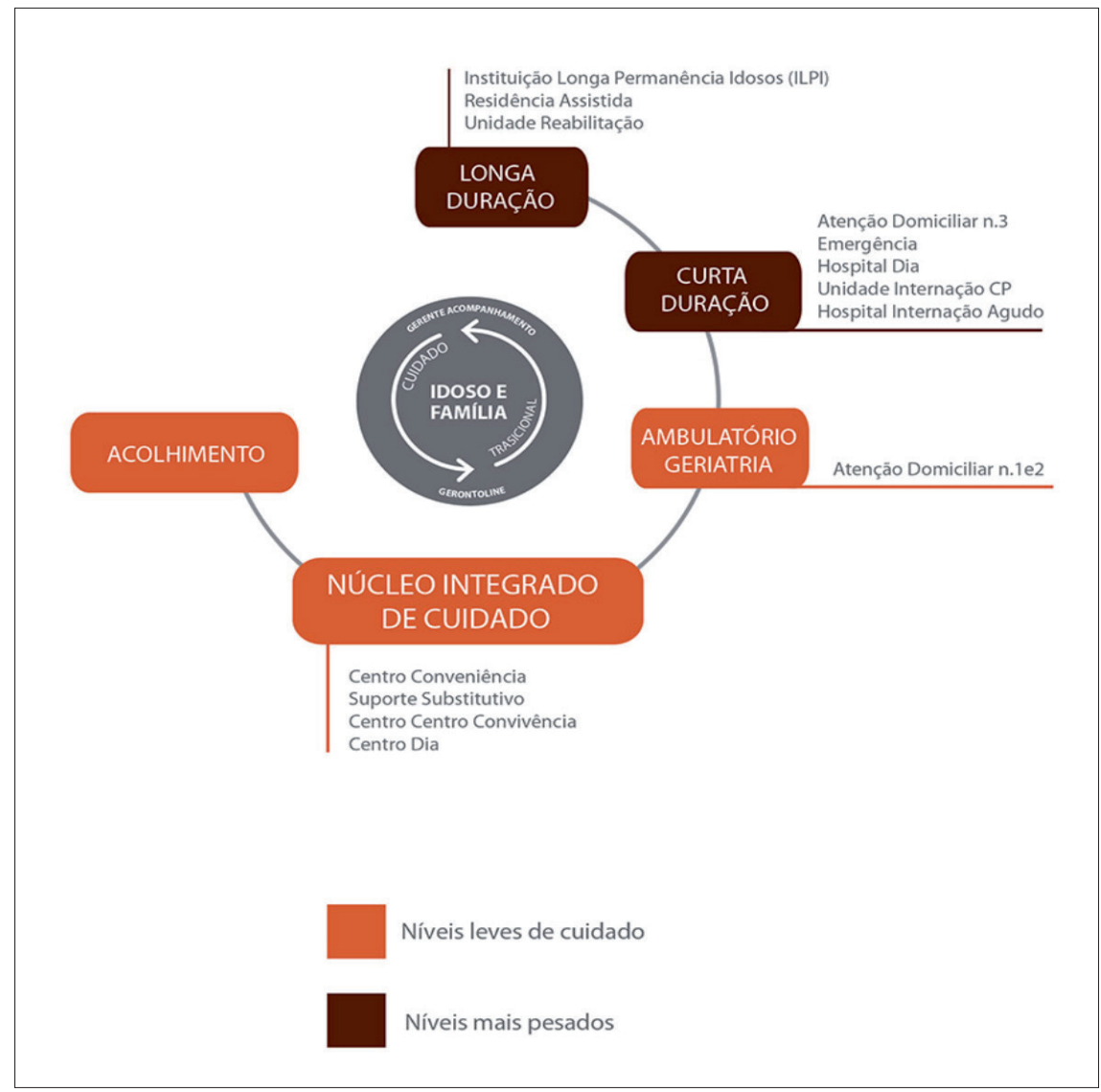

Um importante esclarecimento refere-se ao médico do paciente. A centralidade deste modelo se dá por meio do médico gestor ou médico assistente. Este profissional é o condutor do processo. Caso ele precise de um parecer ou considere que necessita da intervenção de um médico que domine uma área específica, o médico assistente encaminhará seu paciente para um especialista. A condução do caso, no entanto, é responsabilidade do generalista. Após a consulta com o especialista, tudo será registrado no prontuário único do paciente e este voltará para o seu médico (VERAS, 2012).

Nos projetos internacionais, o médico generalista ou de família absorve integralmente para si de $85 \%$ a $90 \%$ dos seus clientes, sem necessidade da ação de um médico especialista. Além disso, o médico assistente pode utilizar os profissionais 
de saúde com formações específicas (em nutrição, fisioterapia, psicologia ou fonoaudiologia). Portanto, o cliente terá uma gama muito maior de profissionais ao seu dispor, mas quem indica e encaminha é o médico assistente. Importante também frisar que no Brasil há um excesso de consultas realizadas por especialistas. Isso ocorre porque o modelo atual de assistência prioriza a fragmentação do cuidado. Este problema cultural fica evidenciado ao se observar o modelo inglês, o National Health Service (NHS), que tem como figura central de organização os general practitioners (GPs), médicos generalistas com alta capacidade resolutiva, permitindo estabelecer a fidelização do paciente com o referido profissional. O modelo americano, por sua vez, opta pelo encaminhamento para inúmeros médicos especialistas. Estamos falando de dois países ricos, de grande tradição na medicina, que utilizam modelos diferentes e proporcionam resultados também bastante distintos (VERAS, 2011a).

O início do processo ocorre, por exemplo, quando o novo cliente de um plano de saúde é convidado a conhecer o novo produto que está sendo proposto e todos os esclarecimentos são obtidos através de um profissional de saúde treinado e que desempenha uma função muito mais ampla do que a de um corretor de vendas de plano de saúde, pois é esta a pessoa que faz a primeira abordagem e que explica o funcionamento deste produto que está sendo vendido, visando ao entendimento da proposta e sua real adesão, com foco mais assistencial do que comercial.

Este primeiro atendimento deve ser realizado por um profissional de saúde, com formação em Geriatria ou Gerontologia, normalmente uma enfermeira, que irá explicar a linha do cuidado e suas várias instâncias de atendimento, estabelecendo uma relação de confiança entre usuário (e sua família) e o modelo de cuidado proposto. Essa profissional fará uma ampla exposição das açóes propostas, enfatizando, sobretudo, a promoção da saúde e a prevenção de doenças, além de todos os percursos assistenciais da rede de atenção, permitindo ao usuário uma compreensão abrangente do modelo. Deve-se detalhar de modo claro e didático aos usuários os vários procedimentos que serão realizados, diferenciais que acreditamos serem benéficos e que visam melhorar a qualidade de vida e de saúde dos idosos, do mesmo modo que a participação do idoso deve ser incentivada, porque faz parte deste modelo de atenção à saúde.

Julgamos importante, no entanto, que haja um médico presente na unidade de acolhimento, em caso de dúvida ou na eventualidade de um usuário não aceitar 
determinada informação sobre sua doença. Nesse tipo de conflito (raro, mas que pode ocorrer), o médico tem de intervir. A confiança e a fidelidade ao sistema são consequências da percepção do usuário do quanto ele é respeitado, do que lhe é oferecido e de que há vantagens para ambos: o idoso percebe sua saúde bem cuidada e se sente protegido; a operadora obtém a fidelização com custos mais baixos.

Em função do pequeno conhecimento da sociedade sobre esse modo de cuidar, muitos pacientes e seus familiares poderão ficar em dúvida em optar por um cuidado baseado numa atenção primária forte e com médicos de porta de entrada generalistas ou geriatras. Ainda temos uma cultura muito forte de que a possibilidade do "selfservice" de especialistas e de exames seria uma "garantia" para um bom acesso à saúde. Mas todas as experiências demonstram que, uma vez experimentando um novo modelo de cuidado, baseado na boa prática e na prevenção e manutenção da funcionalidade, a adesão é sempre muito boa.

Nesse espaço de acolhimento também estarão disponíveis materiais educativos para que, de acordo com a necessidade do usuário, seja possível iniciar a orientação sobre patologias crônicas, como hipertensão, diabetes e osteoartrite, além do uso seguro de medicação, nutrição saudável, segurança ambiental, atividade física e orientações sobre vacinas e exames periódicos. Durante o acolhimento, é aberto um registro eletrônico único, longitudinal e multiprofissional. Lá estarão armazenadas as informaçôes de todas as instâncias de cuidado do modelo assistencial, desde o primeiro contato até o cuidado paliativo na fase final da vida. Esse registro deve conter informaçôes sobre a história clínica e os exames físicos do paciente idoso, mas é essencial que tenha informaçôes sobre seu dia a dia, sua família, apoio social, entre outras. Seu prontuário deverá também contar com os registros dos demais profissionais da área da saúde, como fisioterapeutas, nutricionistas e psicólogos, entre outros.

Este modelo é pautado pelo monitoramento do paciente em todos os níveis, verificando a efetividade das açôes para tomada de decisóes e acompanhamento. Como forma de organizar o acesso aos níveis do modelo, é realizada uma triagem epidemiológica básica, de poucas perguntas que permitam identificar algumas características operacionais para priorizar o atendimento e utilizar os recursos adequadamente, por meio da aplicação de um instrumento breve de identificação de risco (IR). A tomada de decisão técnica sobre o encaminhamento do cliente precisa ocorrer mediante a pactuação do envolvimento na proposta de atenção à saúde e com 
base na avaliação do risco de incapacidade. Desse modo, o IR "organiza a demanda", definindo prioridades com base na necessidade e não na perversa busca de senha para atendimento. O importante é que a identificação de risco seja aplicada em todos os usuários em seu ingresso no modelo. Pode ser autoaplicável, anterior à ida ao acolhimento (nível 1), permitindo uma acolhida ao usuário com informaçôes prévias.

Existem vários instrumentos validados e que preenchem todos os requisitos científicos de qualidade. Para a porta de entrada, no nível 1, sugerimos o questionário Prisma-7, que tem sido utilizado sistematicamente na porta de entrada do sistema de saúde do Canadá (onde foi desenvolvido) e pela British Geriatrics Society e pelo Royal College of General Practitioners, na Inglaterra, como instrumento de rastreio para perda funcional e fragilidade. Composto de sete itens, apresenta como benefícios a facilidade e rapidez da aplicação e das respostas (do tipo sim/não), maior objetividade, menor risco de parcialidade do entrevistador, menor possibilidade de erros e maior facilidade na análise dos resultados (SAENGER, CALDAS, MOTTA, 2016).

O processo de validação e adaptação transcultural do questionário Prisma-7 para o Brasil mostrou que o ponto de corte referente à pontuação 4 (quatro ou mais respostas positivas) é o ideal. $\mathrm{O}$ instrumento não requer material especial, qualificação ou treinamento. O tempo de aplicação é de três minutos e os níveis sociocultural e de escolaridade não influenciaram na compreensão das questôes.

Além da identificaçáo de risco realizada no acolhimento, na fase inicial do processo, os demais instrumentos epidemiológicos serâo utilizados anualmente a partir da etapa posterior, ou seja, o nível 2. As informaçóes farão parte do prontuário eletrônico do paciente e serão mantidas até o final do percurso assistencial. O médico e o seu gerente de acompanhamento, além da equipe interprofissional geriátrica, farão avaliações mais detalhadas, a fim de propor um plano de intervenção.

Propomos que a ratificação da adesão ao "novo produto" do plano de saúde ou ao novo modelo de assistência seja realizada durante o acolhimento, como forma de garantir que todos os esclarecimentos sejam prestados e não haja nenhuma dúvida por parte do cliente, possibilitando, desse modo, um início de relacionamento transparente. $\mathrm{O}$ início desta nova relação deve ser pautado em aspectos técnicos assistenciais, além das questôes administrativas e financeiras inerentes ao contrato terapêutico - nada deve ser omitido. 
A entrevista qualificada de adesão é um momento de grande importância durante a contratação de um plano de saúde, pois, além de criar uma relaçáo de confiança entre as partes, permite que o foco não seja exclusivo na relação contratual. É uma oportunidade única para avaliaçáo do paciente e sua inserção na rede de cuidados. É parte integrante do contrato o preenchimento do documento de saúde (declaração de saúde), no qual são informadas todas as possíveis doenças ou lesôes preexistentes (DLP) e se estabelece a cobertura parcial temporária (CPT). Seu preenchimento é necessário para compreender o contrato a ser assinado, definindo prazos de carência, procedimentos cobertos nos casos de urgência e emergência e cobertura oferecida nos casos de DLP. O preenchimento indevido pode caracterizar uma situação de fraude, ficando sujeito à suspensão da cobertura ou à rescisão unilateral do contrato.

A relação com o usuário precisa mudar. Deve-se estabelecer um pacto baseado em verdades. As açóes realizadas devem ser registradas no sistema de informaçóes, que deve ser aberto no acolhimento e seguido até o final da vida do paciente (LIMA et al., 2016). O ideal é que haja um Registro Eletrônico de Saúde (RES), que é um repositório eletrônico de informaçôes a respeito da saúde dos usuários. Idealmente, esse repositório precisa ter padróes mínimos para que seja acessível em qualquer instância do sistema e pelo próprio paciente. Sinaliza-se que na concepção e implementação do RES devem estar contemplados requisitos de sigilo e privacidade de dados pessoais dos pacientes, com níveis de acesso diferenciados conforme a natureza da informação disponibilizada, em acordo à legislação federal em vigor sobre o tema. Um diferencial importante é a proposição de registrar os "percursos assistenciais" do paciente, por meio de um sistema de informação amplo, que anote não somente a evolução clínica da pessoa idosa, mas também sua participação em açôes de prevençáo individuais ou coletivas.

Após a aplicação do instrumento de triagem rápida no nível 1, o resultado obtido vai para o sistema de informação. $\mathrm{O}$ idoso fará novas avaliaçôes funcionais em outras instâncias de cuidado. No nível 1, será realizado apenas o Prisma-7. Nos níveis 2 e 3, o paciente será submetido aos demais instrumentos que fazem parte dessa avaliação funcional. A Escala de Katz, que avalia as atividades de autocuidado na vida diária, e a Escala de Lawton, para as atividades instrumentais, são exemplos de instrumentos universalmente utilizados. Na nossa proposta, utilizaremos alguns dos importantes protocolos já traduzidos e validados no Brasil. ${ }^{5}$ 
O gerente de acompanhamento (navegador) é um profissional da área de saúde (geralmente, um enfermeiro) que acompanha o idoso e sua família a partir do nível 2 (Núcleo Integrado de Cuidado). A avaliação funcional breve feita no ingresso permite um marco zero de monitoramento e serve de parâmetro para acompanhamento do plano terapêutico entre os diferentes pontos da rede. Esse profissional é responsável pela transição do cuidado entre os serviços e reavalia anualmente, ou quando necessário, a capacidade funcional da pessoa, incentivando-a a participar do processo. Sua função é de extrema importância para o modelo proposto e sua atuação segue a mesma lógica do navegador (navigator) americano, criado para orientar os pacientes com câncer a circular dentro da rede de cuidados e seguir os protocolos. Para manter a qualidade da assistência, sugere-se que cada navegador (gerente de acompanhamento) tenha até 375 idosos $^{6}$ sob sua responsabilidade, ${ }^{7}$ como forma de garantir o estabelecimento da confiança e da vinculação com o idoso, valores inerentes a uma assistência qualificada.

A função do navegador está presente em algumas operadoras dos Estados Unidos e seu papel é central nessa proposta. De acordo com a Associação Médica Americana, é responsabilidade desse profissional o gerenciamento do cuidado do usuário ao longo dos diferentes níveis de complexidade do sistema de saúde, verificando se as prescrições e orientaçoôes estão sendo cumpridas.

O médico do paciente, aquele médico da família de antigamente, atende no ambulatório localizado no nível 2 do modelo, mas acompanha o idoso em todas as instâncias de cuidado. Caso o paciente seja internado no hospital, o médico não o assistirá nessa unidade da rede, porém, como seu responsável e ponto de referência, ele será informado de tudo que acontece, ao lado do seu enfermeiro, e manterá contato com o médico do hospital, da internação domiciliar ou de qualquer outra instância de cuidado. O importante é garantir que todo cliente terá seu médico e este o acompanhará, independentemente do local da assistência. A relação entre médico, gerente de acompanhamento e paciente deve ser intensa. 


\section{Figura 2. Projeto Idoso Bem Cuidado}



Fonte: Elaboração própria

As figuras 1 e 2 seguem a lógica do cuidado, da integralidade e da busca pelas mudanças necessárias. É preciso inovar no cuidado, na forma de remunerar e avaliar a qualidade ofertada. Vale a pena ressaltar a ênfase conferida ao modelo assistencial e à remuneração, como pode ser visto na figura 2, nas duas plataformas sobrepostas: uma relativa ao modelo assistencial e outra relativa ao modelo de remuneraçáo.

A figura 2 foi apresentada no livro Idosos na Saúde Suplementar: uma urgência para a saúde da sociedade e para a sustentabilidade do setor, do Projeto Idoso Bem-Cuidado, da ANS (BRASIL, 2016). Mostra, com importância semelhante, a qualidade do cuidado oferecido pelo médico assistente, sua carteira de clientes e sua remuneraçáo variável. Ênfase também é conferida, no centro do gráfico, à carteira de clientes, às avaliaçóes funcionais, ao rastreamento de risco, ao gerenciador de cuidados e a um 
eficiente sistema de informações, que registra todas os eventos dos clientes. Também é destacada a importância das várias instâncias de cuidado, como o ambulatório, o hospital, a atenção domiciliar, a reabilitação, a equipe multidisciplinar, o centro de convivência e o cuidado paliativo. Todas fazem parte da rede de cuidado e estáo integradas por meio do sistema de informação e do seu médico assistente, que é a referência clínica por todo o seu percurso no modelo. Fica bastante evidente que o hospital é apenas uma das instâncias. Está em igualdade com as demais, mas superado pela importância das açóes preventivas, que estão no centro do modelo. A lógica, nas instâncias leves, é do cuidado integral, da equipe multidisciplinar e do médico responsável pelo paciente.

A figura 1 apresenta o sumário gráfico do modelo desenvolvido pela Universidade Aberta da Terceira Idade (UnATI/UERJ), no centro estão colocados alguns elementoschave. Há a preocupação de incluir o idoso e sua família, um destaque para a figura do navegador e do GerontoLine, ou seja, estruturas que reforçam a centralidade no cliente e em sua família e as facilidades de comunicação entre profissionais de saúde e cliente. Também há uma mensagem relevante ao estruturar o modelo em cinco segmentos, com cores distintas para os grupos 1 a 3 (instâncias de cuidado mais leves) e para os grupos 4 e 5 (instâncias mais pesadas). O detalhamento dos cinco grupos permite melhor entendimento da filosofia baseada na funcionalidade, não na doença.

Ainda na figura 1, no nível 2, encontra-se o Núcleo Integrado de Cuidado, uma unidade que se caracteriza por ser o ponto de atenção da rede. Inclui sistemas de apoio à vida autônoma e independente, com açôes de alimentação, serviços de suporte à família, GerontoLine, centro de convivência e conveniência (local onde se podem adquirir facilidades para os idosos - equipamentos variados, compra de pacotes de turismo, ingressos e transportes para lazer, como teatros e visitas a museus, ou seja, tudo que facilite a vida do idoso e seus familiares), além de serviços de reabilitação e apoio ao cuidado e ao autocuidado. Trata-se, enfim, do coração do modelo, onde serão realizadas todas as articulaçôes para as demais unidades, a partir das avaliaçôes. As açóes realizadas no Núcleo Integrado de Cuidado visam facilitar uma vida ativa para idosos autônomos e independentes, bem como oferecer facilidades de equipamentos de suporte para auxiliar as famílias com idosos dependentes. Além disso, há outros sistemas de apoio para auxiliar o autocuidado, incluindo a supervisão da administração de medicamentos e o agendamento de consultas (LIMA et al., 2015). 
O nível 2 é o local de integração das várias ações de educação, promoção e prevenção de saúde por intermédio de ambulatório para idosos com baixo risco, centro de convivência e conveniência, serviços de reabilitação, serviços de apoio ao cuidado e ao autocuidado, apoio à família e local onde consolida a relação do seu gerente de acompanhamento e seu médico assistente. $\mathrm{O}$ idoso que apresenta risco baixo e moderado será acompanhado ambulatorialmente. Dependendo da avaliação realizada, será possível decidir se a intervenção necessária está no nível ambulatorial clínico ou geriátrico. ${ }^{8}$

O GerontoLine é um serviço de apoio onde o idoso e seus familiares sintam-se protegidos, tenham suas necessidades atendidas e suas dúvidas esclarecidas sobre a assistência recebida. Deve funcionar como um diferencial, exercendo o papel de facilitador e reforço na relação com o paciente. A equipe de atendentes deve ser formada por pessoal qualificado, sob a coordenaçáo de um profissional com formação em psicologia, e seu papel será o de conversar com o cliente e atender suas demandas. A prerrogativa é que toda situação tenha uma solução satisfatória. Caso necessário, o atendente deve retornar à ligação com a resposta que não puder ser oferecida no momento anterior.

Com relação aos familiares da pessoa idosa, observamos que há modelos distintos, com arranjos variados, do que podemos considerar como participação existem idosos que vivem sós, sem suporte de uma rede familiar, e isto não quer dizer que não haja amigos ou empregados; outros convivem com acompanhantes; uns são assistidos a distância; e ainda há aqueles que vivenciam relaçóes pautadas nas obrigaçôes morais sem afeto. $\mathrm{O}$ suporte não deve se restringir à relação familiar consanguínea, mas ser extensivo àqueles que vivem ou convivem com o idoso. Ressaltam-se, assim, aspectos ausentes na maioria dos modelos assistenciais para pessoas idosas existentes no país e que, quando devidamente registrados em sistema único de informaçôes, proporcionam algo muito importante para o cuidado: quanto mais o profissional de saúde conhece o histórico do seu paciente, melhores serão os resultados, e é assim que devem funcionar os modelos contemporâneos e resolutivos de cuidado (RAMOS et al., 2013).

A participação da família, a explicação das atividades do "núcleo integrado de cuidado" (nível 2) e os screenings epidemiológicos decorrentes de atendimentos nos serviços ofertados são outros importantes diferenciais deste produto. A informação 
sobre todos os procedimentos é fundamental para o monitoramento do associado e a confecção do cartão do cliente, que tem um chip contendo número de registro, nome do contato familiar, unidade em que é atendido, médico e enfermeira responsáveis, um sumário de importantes eventos e o acesso ao seu registro eletrônico.

O terceiro nível (ambulatório especializado ou geriátrico) está estruturado para atender idosos com sínd rome geriátrica e fragilizados ou em processo de fragilização, os quais necessitam de acompanhamento especializado, mais pormenorizado e de maior complexidade. O acompanhamento é realizado por equipe multiprofissional, voltando sua abordagem para a manutenção e reabilitação da funcionalidade. Trata-se de um ambulatório geriátrico, voltado para o idoso mais frágil ou de maior risco, que demanda esse tipo de intervenção. As açôes visam interromper/ diminuir a evolução da fragilidade, paralelamente à redução dos custos. $\mathrm{O}$ atendimento domiciliar (consulta e procedimento) também pertence a essa estação de cuidado. Nele destacamos a importância da equipe multidisciplinar composta por médico, enfermeiro e assistente social. Eles realizam a avaliaçáo geriátrica multidimensional, que permitirá intervençôes específicas quando necessário. Esta avaliação considera aspectos médicos, de cuidados, de suporte social, de meio ambiente, cognitivos, afetivos, de crenças religiosas e econômicas que constituem o plano terapêutico, construído coletivamente e discutido com a equipe de saúde e a navegadora. Este também é o local onde se encontra o atendimento domiciliar de baixa e média complexidades.

Como já mencionado, é essencial saber o quanto as doenças crônicas impedem o idoso de exercer suas atividades rotineiras de forma autônoma e independente. É no nível 3 que a avaliação geriátrica multidimensional será aplicada, pois é um instrumento importante para precisar um diagnóstico, um prognóstico e um julgamento clínico adequado para um planejamento assistencial efetivo. A prática médica mostra que a diminuição da capacidade funcional do idoso é que o tornará dependente de um nível mais complexo de assistência. E ela poderá ser ocasionada pela evolução da própria patologia de base, por sua má administração e sequelas ou pela inadequada assistência recebida - seja familiar, social ou institucional.

$\mathrm{O}$ atendimento domiciliar constitui uma modalidade de atenção substitutiva ou complementar às já existentes, caracterizada por um conjunto de açôes de promoção à saúde, prevenção/tratamento de doenças e reabilitação prestadas em domicílio, 
com garantia de continuidade e integração a redes de cuidados. A atenção domiciliar pode ser disponibilizada em três categorias diferentes:

- atendimento domiciliar nível 1: adequado a pacientes idosos, que residem só e têm dificuldade de deambular. Neste caso, se o serviço não for domiciliar, o idoso fica sem assistência e seu quadro só tende a se agravar. Na verdade, esta modalidade de nível 1 é semelhante a uma consulta ambulatorial no domicílio;

- atendimento domiciliar nível 2: utiliza tecnologia relativamente simples e é indicado para quando o paciente necessita de procedimento que pode ser realizado no domicílio, como reabilitação após fratura, cicatrização de feridas e outras convalescenças após internação hospitalar;

- atendimento domiciliar nível 3: utiliza estrutura bastante semelhante à do hospital e funciona bem para os idosos, pois permanecem em sua residência e no seu quarto, sem riscos de infecção hospitalar e em um ambiente ao qual está acostumado.

O quarto e o quinto níveis do modelo devem ser usados com parcimônia, em momentos precisos e sempre com o acompanhamento da equipe do projeto. Dividimos as instâncias de cuidado mais "pesadas" (em marrom no gráfico) em dois grupos: os de curta duração e os de longa duração (VERAS, 2011b).

É no quarto nível que se encontra o atendimento domiciliar de maior complexidade, pois apostar em instalaçóes hospitalares e espaços para tratamentos ultra-especializados é ir contra uma tendência que aponta para o risco de amargas perdas - sejam econômicas ou do ponto de vista do cuidado. $\mathrm{O}$ avanço tecnológico das últimas décadas proporcionou a miniaturização e automação de equipamentos de alta tecnologia, como os respiradores mecânicos, as bombas de infusão, as máquinas de diálise e os equipamentos de administração de medicamentos, tornando-os mais usuais, simples e de mais baixo custo. Pode-se, portanto, transferir parte da parafernália hospitalar para o interior da residência do paciente.

Procedimentos cirúrgicos que demandavam vários dias de internação foram reduzidos à metade. Procedimentos vários que antes demandavam hospitalização são realizados em consultórios/ambulatórios, trazendo mais conforto, reduzindo as chances de infecção hospitalar, além de uma conta menor para o pagador. Estes fatores levam a uma menor utilização do hospital, com a consequente ampliação dos procedimentos realizados no próprio lar (home-care). 
Sabemos que sempre iremos necessitar de bons hospitais. Além do mais, nem todos os pacientes e residências são elegíveis para o tratamento domiciliar. Não é propósito, portanto, passar uma concepção niilista. O que não é razoável é transformarmos os hospitais em porta de entrada do sistema de saúde, quando a medicina mais contemporânea mostra que essa instância de cuidado, além de mais cara, deve ficar restrita a indicações precisas. O home-care não é um modismo, apenas uma modalidade mais contemporânea de cuidar. Aliás, a "invenção" do moderno hospital é que é algo recente. Até bem pouco tempo atrás, o cuidado se



À semelhança dos níveis anteriores, o nível 4 também trabalha com a lógica preventiva e tem por objetivo reduzir a progressão e as complicaçóes de uma doença já sintomática, sendo aspecto importante da terapêutica e da reabilitação. Sabemos da importância do hospital e não desprezamos sua capacidade no processo de recuperação de um doente, mas esta instância deve ser reservada para casos bem específicos e definidos, e pelo menor período possível. Após a remissão da fase aguda, a assistência domiciliar pode ser o melhor local de continuação do tratamento. Reservamos os hospices ou cuidados paliativos, na fase terminal, para um curto período e para casos específicos. O mesmo se aplica as outras instâncias do nível 4, que se caracteriza por um acompanhamento de curto prazo e pelo encaminhamento para uma instância mais adequada tão logo seja possível. No nível 4, o tempo de internação deve ser curto, inclusive no segmento hospice ou na Unidade de Internação de Cuidados Paliativos, que deve ser utilizada apenas em fase terminal, visando amenizar todas as formas possíveis de sofrimento.

No nível 5, observa-se uma grande contradição na lógica assistencial. Embora reconhecidas na área da saúde, as instâncias de longa duração não contam com cobertura do setor privado. No setor público, por sua vez, esses locais têm sua gestão transferida para instituiçôes filantrópicas, religiosas ou para o segmento social do governo. Infelizmente, as instâncias de longa duração são vistas como depósitos de idosos doentes, particularmente os asilos, locais que, em sua maioria, funcionam como repositório de problemas sociais, de abandono e de muito pouca atenção da área da saúde.

Não deveria ser assim, pois nesse nível se encontra a unidade de reabilitação para casos que exijam acompanhamento por longo período. Já as residências assistidas são alternativas interessantes para manter o idoso sob proteção da família, em local não 
institucionalizado, preservando os laços afetivos e um apoio afetivo mais intenso. As instituições de longa permanência para idosos precisam ser uma opção para o cuidado ao idoso no Brasil assim como são em outros países. Em suma, o nível 5 de cuidado exige uma política mais inclusiva e uma participação mais efetiva dos setores público e privado para evitar o abandono no último período da vida. Como são açôes de longo curso, a discussão fundamental diz respeito à estruturação de um mecanismo de financiamento, caso contrário pouco avanço será alcançado.

Para o sucesso desse modelo, portanto, é preciso que os clientes sejam orientados a fazer parte dos programas e açôes propostas, em vez da lógica vigente de utilizar o plano de saúde apenas quando da realização de exames ou da entrada em um hospital já com doença em estágio avançado. O modelo reúne todas as instâncias de cuidado, não exclui absolutamente nada em relação à assistência requerida - aliás, inclui novos equipamentos em saúde, praticamente não disponíveis no sistema de saúde suplementar - e prioriza a lógica do cuidado em instâncias mais “leves”. Nelas se oferece a melhor assistência possível, com profissionais treinados e qualificados, baseados nas modernas concepçóes científicas de atendimento. Em síntese, nossa proposta é investir na saúde para reduzir o gasto com a doença.

\section{Tendência de mudança}

A preocupaçáo com um modelo de cuidado ao idoso de maior qualidade e mais efetivo não é somente brasileira. $\mathrm{O}$ mundo todo está debatendo o tema, reconhecendo a necessidade de mudanças e propondo melhorias em seus sistemas de saúde (BANCO MUNDIAL, 2011).

O mesmo ocorre entre nós, ao apresentarmos os estudos realizados na UnATI/ UERJ e no projeto Idoso Bem-Cuidado, da ANS: verifica-se que os gráficos resumem este conceito e sintetizam de forma perfeita o modelo que buscamos. Não existe um modelo único, mas uma lógica que privilegia as instâncias leves, o monitoramento constante, um serviço telefônico eficiente, as tecnologias embarcadas, o médico responsável por uma carteira de clientes e que o acompanha em todas as instâncias de cuidado, um enfermeiro que trabalha em dupla com seu médico, o trabalho em equipe, o uso do instrumental epidemiológico para monitorar a funcionalidade e um prontuário eletrônico de qualidade. Todos esses elementos fazem um contraponto ao modelo baseado nos médicos especialistas, na desarticulação dos profissionais, no 
uso prioritário do hospital e das emergências, no consumo elevado de fármacos e no excesso dos exames laboratoriais e de imagem (VERAS et al., 2011b).

A busca da excelência e de práticas inovadoras deve ser permanente e constitui um desafio que ultrapassa o conhecimento das ciências biológicas. A interlocução com as ciências sociais e econômicas deve ser permanente, como forma de manter modelos assistenciais mais eficientes, resolutivos, de qualidade superior e custos mais baixos, que possibilitem a redução de riscos (MORAES, 2012). O modelo de cuidado propicia o conhecimento de seus usuários, seu perfil e suas necessidades, de modo a organizar da melhor forma a prestação de serviços.

Importante ressaltar que a proposta apresentada não tem por objeto apenas a discussão de mecanismos de redução dos custos em saúde. Este fator é um elemento importante do contexto, como tantos outros que nos movem em busca de um objetivo mais amplo, que é o cuidado integral do idoso. O modelo apresentado tem por compromisso e meta a melhoria da qualidade e da coordenação do atendimento prestado desde a porta de entrada no sistema e por todo o contínuo do cuidado, evitando redundâncias de exames e prescrições, interrupçôes na trajetória do usuário e a iatrogenia gerada pela desarticulação das intervençôes em saúde.

O hospital e a emergência sempre serão instâncias de cuidado importantes para a atenção à saúde, mas é preciso redefinir e recriar a função que exercem na rede assistencial atualmente. Estas unidades de cuidado devem ser reservadas prioritariamente para os momentos de agudização da doença crônica (CALDAS et al., 2015).

Uma coisa é certa: sem a organização do cuidado do idoso e a elaboração de um plano de cuidados, o envelhecimento populacional e o aumento da prevalência de doenças crônicas no setor público ou suplementar de saúde brasileiro podem deixar de ser oportunidades e se tornar entraves à própria sustentabilidade do sistema.

\section{Conclusão}

A proposta deste modelo de cuidado integrado para o idoso configura-se como um fluxo de ações de educação, promoção da saúde, prevenção de doenças evitáveis, postergação de moléstias, cuidado precoce e reabilitação de agravos (LIMA-COSTA; VERAS, 2003). Ou seja, uma linha de cuidado para o idoso que seja um percurso assistencial por dentro de uma rede articulada, referenciada e com um sistema de informação desenhado em sintonia com essa lógica. 
Transformar a lógica do cuidado em saúde no Brasil é um grande desafio e também uma necessidade. E ganha uma relevância ainda maior quando falamos da atenção à saúde de pessoas em situaçôes de maior vulnerabilidade, como é o caso dos idosos. Esse tipo de mudança e inovação precisa ser construída no cotidiano dos serviços, na formação dos profissionais de saúde, na forma como o sistema de saúde é gerido e organizado para a assistência e em seu financiamento. Não há como falar de reorganização da prestação dos serviços sem falar de modelos de remuneração, pois um determina e reforça o outro. Precisamos enfrentar esse debate para avançar em direçâo a uma maior qualidade do cuidado em saúde e para que seja possível remunerar de forma adequada outras instâncias de cuidado e novas maneiras de produzir saúde - como o Núcleo Integrado de Cuidado e as instâncias de cuidado de transição e paliativo -, imprescindíveis em um cenário de prevalência de doenças crônicas.

Acreditamos ser possível envelhecer com saúde e qualidade de vida, desde que todos os atores do setor se percebam responsáveis pelas mudanças necessárias e se permitam inovar. Inovar no cuidado, na forma de remunerar e avaliar a qualidade do setor. Importante lembrar sempre que, muitas vezes, inovar significa resgatar cuidados e valores mais simples, que se perderam dentro do nosso sistema de saúde. Já perdemos muito tempo; precisamos agora iniciar a construção dessa nova forma de cuidar dos idosos. Não podemos mais esperar. ${ }^{10}$

\section{Referências}

BANCO MUNDIAL. Envelhecendo em um Brasil mais velho: implicaçôes do envelhecimento populacional para o crescimento econômico, a reduçấo da pobreza, as finanças públicas e a prestação de serviços. Washington, DC: The World Bank, 2011.

BRASIL. Ministério da Saúde. Agência Nacional de Saúde Suplementar. Plano de cuidado para idosos na saúde suplementar. Rio de Janeiro: ANS, 2013. 62 p.

- Ministério da Saúde. Agência Nacional de Saúde Suplementar. Idoso na saúde suplementar: uma urgência para a saúde da sociedade e para a sustentabilidade do setor. Rio de Janeiro: ANS, 2016. 132p.

CALDAS, C. P. et al. Atendimento de emergência e suas interfaces: o cuidado de curta duração a idosos. J Bras. Econ. Saúde, v. 7, p. 62, 2015.

FOUCAULT, M. Microfisica do Poder. Rio de Janeiro: Graal, 1990. 
LIMA, K. C. et al. Effectiveness of intervention programs in primary care for the robust elderly. Salud Pública de México, v. 57, p. 265-274, 2015.

. Health promotion and education: a study of the effectiveness of programs focusing on the aging process. Int J Health Serv, Aug. 2, 2016.

LIMA-COSTA, M. F.; VERAS, R. P. Saúde pública e envelhecimento. Cad. Saúde Pública, v. 19, n. 3, p. 700-1, 2003.

MENDES, E. V. et al. Prospecção de evidências científicas para a tomada de decisão na gestão da saúde pública: a experiência da Secretaria de Estado de Saúde de Minas Gerais. Revista Mineira de Saúde Pública, p. 24-34, 2004.

MORAES, E. N. Atenção à saúde do idoso: aspectos conceituais. Brasília: OPAS, 2012.

RAMOS, L. R. et al. Perguntas mínimas para rastrear dependência em atividades da vida diária em idosos. Revista de Saúde Pública, Rio de Janeiro, v. 47, p. 506-513, 2013.

SAENGER, A. L. F.; CALDAS, C. P.; MOTTA, L. B. Cross-cultural adaptation of the PRISMA-7 instrument for use in Brazil: evaluation of conceptual, item, and semantic equivalences. Cad. Saúde Pública, Rio de Janeiro, v. 32, n. 9, 2016.

VERAS, R. P. Estratégias para o enfrentamento das doenças crônicas: um modelo em que todos ganham. Revista Brasileira de Geriatria e Gerontologia, v. 14, p. 779-786, 2011 b.

. Experiências e tendências internacionais de modelos de cuidado para com o idoso.

Revista Ciência e Saúde Coletiva, 2011a. Disponível em: < http://www.scielo.br/pdf/csc/v17n1/ a25v17n1.pdf>.

. Prevenção de doenças em idosos: os equívocos dos atuais modelos. Cad. Saúde Pública, Rio de Janeiro, v. 28, p. 1834-1840, 2012.

VERAS, R. P. et al. A urgente e imperiosa modificação no cuidado à saúde da pessoa idosa. Revista Brasileira de Geriatria e Gerontologia, Rio de Janeiro, v. 18, n. 1, p. 5-6, 2015.

. Desenvolvimento de uma linha de cuidados para o idoso: hierarquização da atenção baseada na capacidade funcional. Revista Brasileira de Geriatria e Gerontologia, Rio de Janeiro, v. 16, n. 2, p. 385-392, 2013.

. Integração e continuidade do cuidado em modelos de rede de atenção à saúde para idosos frágeis. Revista de Saúde Pública. São Paulo, v. 48, p. 357-365, 2014.

VERAS, R. P.; AMORIM, A, E. Modelo de Atenção à Saúde do Idoso: a ênfase sobre o primeiro nível de atenção, In: LOZER, A. C. et al. (Org.). Conhecimento técnico-científico para qualificação da saúde suplementar. Brasília, DF: OPAS, 2015, p. 73-84.

VERAS, R. P.; CALDAS, C. P.; CORDEIRO, H. A. Modelos de atenção à saúde do idoso: repensando o sentido da prevenção. Physis: Revista de Saúde Coletiva, Rio de Janeiro, v. 23, n. 4, p. 1189-1213, dez. 2013. 
VERAS, R. P.; ESTEVAM, A. Modelo de Atenção à Saúde do Idoso - a ênfase sobre o primeiro nível de atenção. In: LOZER, A. C. et al. (Org.). Conhecimento técnico-científico para qualificação da saúde suplementar. Brasília, DF: OPAS, 2015, p. 73-84.

\section{Notas}

${ }^{1}$ Linhas de cuidado são estratégias de estabelecimento do percurso assistencial, com o objetivo de organizar o fluxo dos indivíduos de acordo com suas necessidades.

${ }^{2}$ Preferencialmente, essas açóes devem ser oferecidas em um local intitulado Núcleo Integrado de Cuidado, como será detalhado adiante.

${ }^{3}$ Para o início dessa nova lógica, o acolhimento deve ter, preferencialmente, local próprio, mas também pode se localizar no interior de uma das instâncias de cuidado da operadora.

${ }^{4}$ GerontoLine é a denominação que demos para um call-center qualificado e resolutivo.

${ }^{5}$ Triagem rápida - Prisma-7; Sumário - Triagem funcional do idoso (rastreamento funcional de Lachs); Escala de atividades básicas de vida diária (escala de Katz); Escala de atividades instrumentais de vida diária (Escala de Lawton); Miniavaliação nutricional (escala de Vellas); Teste de equilíbrio e marcha (escala de Tinetti); Cartão de Jaeguer (escala visual); Miniexame do estado mental (teste de Folstein); Escala de depressão geriátrica (escala de Yesavage).

${ }^{6} \mathrm{O}$ número de 375 pacientes é calculado para uma jornada de trabalho de 20 horas semanais. O navegador trabalha em dupla com o médico, tomando conta de uma carteira de clientes.

${ }^{7}$ Para 20 horas semanais de trabalho do médico e do enfermeiro navegador, sugerimos uma carteira de 375 clientes.

${ }^{8} \mathrm{O}$ ambulatório clínico localizado no nível 2 é aquele onde estarão os idosos com uma patologia de baixa demanda. O nível 3 é para os idosos de múltiplas patologias e que necessitam de um apoio geriátrico mais robusto.

${ }^{9}$ O importante pensador e filósofo francês Michel Foucault (1926-1984), no seu livro Microfísica do Poder, no capítulo "O nascimento do hospital", faz importantes revelações sobre os levantamentos históricos e reflexóes sobre o hospital. Esse capítulo está baseado na Conferência realizada no Instituto de Medicina Social da UERJ, em 1974, com tradução de Roberto Machado. Foucault revela que: "O hospital como instrumento terapêutico é uma invenção relativamente nova, que data no final do século XVIII”, pois até então o cuidado com a saúde era algo realizado no interior das casas, sem um espaço apropriado para tal procedimento.

${ }^{10}$ M. R. de Oliveira participou da revisão bibliográfica, redação do artigo e de debates sobre o tema com os outros autores. R. Veras, da coordenação da discussão com os outros autores, inclusão de novas bibliografias e revisão do texto. H. Cordeiro, da leitura de todo material, sugestôes e revisão final do texto. 


\section{Abstract}

The importance of the gateway in the system: the integral model of care for the elderly The literature shows that the provision of services to the elderly should be more efficient. Users need services that integrate primary care and other services, as well as qualified health staff. The care plan and management are key elements for the success of the care. There is a need to modify the healthcare model, starting with the integration and coordination of services. This text is based on two successful healthcare models for the elderly, that of UnATI-UERJ and the Well-Cared Elderly Project, an initiative of the National Supplementary Health Agency that proposes an innovative model of care. Both are comprised of five hierarchical levels of care - (1) care, (2) integrated care center, (3) geriatric outpatient clinic, (4) shortterm complex care and (5) long-term care - the first three stand out, in the light instances of care. Risk identification and completeness of attention at different points in the network are at the heart of this model. The main commitment of the project is to improve the quality and coordination of care from the system's entrance door and throughout care, with consequent better use of system resources, both by health professionals and by users and patients.

Keywords: elderly; health services; integral health care; quality of health care; innovation. 